\title{
Pandemia e interdisciplinaridade: Um novo olhar para a educação
}

\author{
Pandemics and interdisciplinarity: A new look at education \\ Pandemias e interdisciplinaridad: Una nueva mirada a la educación
}

Recebido: 26/10/2021 | Revisado: 06/11/2021 | Aceito: 13/11/2021 | Publicado: 22/11/2021

\author{
Juscélia Paiva dos Santos \\ ORCID: https://orcid.org/0000-0002-6254-8026 \\ Universidade Estadual de Goiás, Brasil \\ E-mail: jusceliapaiva24@gmail.com \\ Zenaide Dias Teixeira \\ ORCID: https://orcid.org/0000-0002-6103-5923 \\ Universidade Estadual de Goiás, Brasil \\ E-mail: zenaide.teixeira@ueg.br \\ Jorge Manoel Adão \\ ORCID: https://orcid.org/0000-0002-2957-613X \\ Universidade Estadual de Goiás, Brasil \\ E-mail: jorgeadao@yahoo.com.br
}

\begin{abstract}
Resumo
O objetivo desse artigo é verificar o impacto da pandemia Covid-19 para repensar a educação fundamentada nos conceitos da interdisciplinaridade, visto que no ano de 2020 a humanidade foi surpreendida pela pandemia do novo Coronavírus, vitimando milhões de pessoas no mundo todo, o que provocou mudanças no modelo educacional vigente. Para desenvolver este artigo, fizemos uma pesquisa de natureza qualitativa. Assim, fizemos uma análise de dados de uma pesquisa realizada pela Associação Brasileira de Educação a Distância (ABED) sobre as aulas remotas na educação básica e realizamos uma entrevista semiestruturada com a diretora de uma escola localizada em Luziânia-GO, a fim de analisar se, apesar dos desafios impostos pela pandemia, foi possível desenvolver, de maneira interdisciplinar, as atividades pedagógicas na escola. As pesquisas apontam que a mudança das aulas presenciais para o ensino remoto foi um imperativo que demandava, em muitos casos, uma mudança no comportamento de professores, alunos, instituição e responsáveis. Portanto, nesse contexto, surgiu uma nova maneira de pensar a educação, advinda das necessidades do momento que incluam o desenvolvimento da sociedade e a importância do trabalho com as questões planetárias, em que a interdisciplinaridade se faz presente como ecoformação, impactando o fazer pedagógico, visando levar os estudantes a repensar a sua realidade, mas fazer isso dentro de um contexto de mundo.
\end{abstract}

Palavras-chave: Interdisciplinaridade; Ecoformação; Educação; Pandemia; Complexidade.

\begin{abstract}
The purpose of this article is to verify the impact of the Covid-19 pandemic to rethink education based on the concepts of interdisciplinarity, since in 2020 humanity was surprised by the new Coronavirus pandemic, victimizing millions of people worldwide, which caused changes in the current educational model. To develop this article, we did qualitative research. So, we made we analyzed data from a survey conducted by the Brazilian Association of Distance Education (ABED) on remote classes in basic education and we conducted a semi-structured interview with the principal of a school located in Luziânia-GO, in order to verify whether, despite the challenges imposed by the pandemic, it was possible to develop, in an interdisciplinary way, the pedagogical activities in the school. Researches show that the change from classroom to remote teaching was an imperative that demanded, in many cases, a change in the behavior of teachers, students, institution and guardians. Therefore, in this context, a new way of thinking about education emerged, arising from the needs of the moment that include the development of society and the importance of working with planetary issues, in which interdisciplinarity is present as eco-training, impacting pedagogical practice, aiming to make students rethink their reality, but to do this within a world context.
\end{abstract}

Keywords: Interdisciplinarity; Ecoformation; Education; Pandemic; Complexity.

\section{Resumen}

El propósito de este artículo es verificar el impacto de la pandemia Covid-19 para repensar la educación con base en los conceptos de interdisciplinariedad, ya que en 2020 la humanidad fue sorprendida por la nueva pandemia de Coronavirus, victimizando a millones de personas en todo el mundo, lo que provocó cambios en la actual. modelo educativo. Para desarrollar este artículo, hicimos una investigación cualitativa. Analizamos datos de una encuesta realizada por la Asociación Brasileña de Educación a Distancia (ABED) sobre clases remotas en educación básica y realizamos una entrevista semiestructurada con el director de una escuela ubicada en Luziânia-GO, con el fin de analizar si, a pesar de los desafíos impuestos por la pandemia, fue posible desarrollar, de manera interdisciplinaria, las actividades pedagógicas en la escuela. Las investigaciones muestran que el cambio del aula a la enseñanza a distancia fue un imperativo que 
exigió, en muchos casos, un cambio en el comportamiento de los docentes, estudiantes, institución y tutores. Por tanto, en este contexto, surgió una nueva forma de pensar la educación, surgida de las necesidades del momento que incluyen el desarrollo de la sociedad y la importancia de trabajar con temas planetarios, en los que la interdisciplinariedad está presente como eco-formación, impactando la práctica pedagógica, con el objetivo de hacer que los estudiantes reconsideren su realidad, pero hacerlo dentro de un contexto mundial.

Palabras clave: Interdisciplinariedad; Ecoformación; Educación; Pandemia; Complejidad.

\section{Introdução}

O ano de 2020 surpreendeu a todos com a pandemia global Covid-19, modificando bruscamente a vida em sociedade. Para Morin (2000), essa crise mostrou o quanto a humanidade está despreparada para as incertezas mundiais. Trouxe-nos também a evidência de que fatos isolados tem influência global e vice-versa. De fato, a fragilidade humana é inegável, a nossa forma de viver teve que ser remodelada. No âmbito educacional interferiu drasticamente no modelo de ensino vigente, assim o processo de ensino teve que ser reinventado, provocando desafios e questionamentos advindos dessa crise planetária.

O pensador francês Morin (2005), propõe a hierarquização e a organização do saber no pensamento contemporâneo. Para ele, os acontecimentos devem ser contextualizados, uma vez que as coisas não acontecem de maneira separada. Assim, defende que somente com a mudança de paradigma será possível pessoas "capazes de compreender e enfrentar os problemas fundamentais da humanidade, cada vez mais complexas e globais" (Morin, 2005, p. 11).

Considera-se que o pensamento pedagógico de Edgar Morin - sobretudo diante do contexto pandêmico, acompanhado pela mudança no formato das aulas, a utilização de artefatos digitais, pelas ações individuais e seu reflexo em temas globais pode gerar novos enredos educacionais para seus atores, que são professores, alunos, pais, mães, responsáveis, líderes comunitários, educadores ambientais etc.

O objetivo desse artigo é verificar o impacto da pandemia Covid-19 para repensar a educação fundamentada nos conceitos da interdisciplinaridade, visto que no ano de 2020 a humanidade foi surpreendida pela pandemia do novo Coronavírus, vitimando milhões de pessoas no mundo todo, o que provocou mudanças no modelo educacional vigente.

\section{Metodologia}

A metodologia utilizada para desenvolver este trabalho é de natureza aplicada, de abordagem qualitativa, na modalidade de estudo de caso na Escola Companhia das Letrinhas ${ }^{1}$, por meio da técnica de entrevista semiestruturada realizada com a diretora da instituição visando analisar o impacto da pandemia na educação. Foi realizado, ainda, um levantamento de informações de uma pesquisa feita pela Associação Brasileira de Educação a Distância - (ABED, 2020), sobre o momento pandêmico vivenciado na educação.

De acordo com Richardson (1999), a pesquisa com métodos qualitativos pode descrever a complexidade de um determinado problema, analisar a interação de certas variáveis e compreender e classificar os processos dinâmicos vivenciados por grupos sociais. As técnicas qualitativas enfocam as experiências das pessoas e seus respectivos significados relacionados aos eventos, processos e estruturas inseridas na cena social (Skinner et al.; 2000).

Para Bogdan e Biklen (1994), a abordagem qualitativa em educação é um procedimento que ajuda a compreender um conjunto de métodos, verificando referenciais teóricos para que possamos mensurar os dados levantados. Os autores corroboram mencionando que:

"Ainda que os indivíduos que fazem investigação qualitativa possam vir a seleccionar (sic) questões específicas à medida que recolhem os dados, a abordagem à investigação não é feita com o objectivo (sic) de responder a questões prévias ou de testar hipóteses. Privilegiam, essencialmente, a compreensão dos comportamentos a partir da perspectiva

\footnotetext{
${ }^{1}$ Para manter em sigilo a identidade da escola, utilizamos um nome fictício.
} 
dos sujeitos da investigação. As causas exteriores são consideradas de importância secundária”. (Bogdan \& Biklen, 1994, p. 17).

A pesquisa qualitativa com a técnica de entrevista semiestruturada leva em consideração a relação ativa entre ambiente e o indivíduo, gerando certo vínculo indissociável entre objeto de estudo e a subjetividade. Desse modo, a partir dos dados levantados por meio da revisão bibliográfica e da entrevista semiestruturada, foi realizada a sistematização, a análise e a discussão desses dados. Tendo em vista que a "abordagem da investigação qualitativa exige que o mundo seja examinado com a ideia de que nada é trivial, que tudo tem potencial para construir uma pista que nos permita estabelecer uma compreensão mais esclarecedora do nosso objeto de estudo". (Bogdan \& Biklen, 1994).

Este estudo se justifica pelo fato de que o isolamento social impôs ao ensino o formato remoto, afetando todos os envolvidos no processo, que se viram obrigados a vivenciar tais mudanças sem nenhum preparo prévio. Toda a comunidade escolar teve sua rotina alterada, um período, de fato, desafiador.

Para tanto, pretende-se analisar se o contexto da pandemia na educação trouxe questões que podem gerar uma mudança de pensamento para a educação em um período pós-pandêmico, considerando a importância da interdisciplinaridade no contexto de situações que interferem em questões globais. Segundo Morin (2015), o conhecimento não é isolado podendo ser expandido e se complexificar, levando a uma inter-relação entre os conhecimentos tidos como parciais ou globais. Por último, este estudo propõe-se analisar se as ações realizadas na disciplina Respeito à Natureza, em uma escola localizada em Luziânia-GO, podem ser consideradas ecoformadoras e interdisciplinares.

\section{Resultado}

\subsection{Tempos de pandemia e reflexões sobre a educação}

A vida de todos os seres humanos no ano de 2020 sofreu alterações provenientes da pandemia causada pela doença covid-19, fomos obrigados a nos isolar socialmente para evitar o contágio pelo coronavírus denominado SARS-COV-2. Inúmeras atividades na sociedade tiveram que se adaptar às novas regras em prol de um bem maior: a sobrevivência. Essa questão nos direciona a (re)pensar o novo normal no cotidiano da vida pública, da vida privada e na sociologia das ausências (Santos, 2020).

Algumas mudanças geram insegurança, assim a comunidade escolar foi uma das mais atingidas. Com escolas fechadas, sem saber como seria o ano letivo de 2020, professores, gestores, estudantes e familiares sentiram-se angustiados. Nesse primeiro momento, mal sabiam eles que passariam por experiências que seriam vistas como propulsoras de um novo pensar.

Após quase três meses sem aulas, surge o Ensino Remoto Emergencial, levando as aulas, que antes eram presenciais, para a forma online, graças ao desenvolvimento tecnológico. Instituições tiveram que se adaptar para a continuidade das aulas, em condições extremamente desafiadoras. Nesse contexto, a Associação Brasileira de Educação a Distância (ABED, 2020) fez uma pesquisa sobre a educação básica, atividades remotas.

Os dados compilados apresentam que $92,15 \%$ das escolas brasileiras realizaram atividades remotas. Foi necessária adaptação para a comunicação digital, com investimentos em plataformas virtuais para postagem de atividades, recursos digitais, convênios com a TV aberta por parte das instituições para transmissão de aulas, dentre outras formas criadas para estabelecer a comunicação com o aluno. Além disso, a escola ainda passou a oferecer, dentro de suas possibilidades, apoio emocional aos alunos e familiares. Na teoria moriniana, considera-se o humano constituído no "entrelaçamento do emocional com o racional" (Maturana, 2002, p. 18).

Na coleta de dados dos estudantes, segundo pesquisa da ABED 2020, 60,58\% dos alunos participou de todas ou quase todas as atividades remotas de sua escola. Outro fator importante é que $29,24 \%$ dos estudantes têm dificuldade de conexão com a internet por causa do sinal das operadoras. No entanto, com o resultado da pesquisa, podemos inferir que, apesar da dificuldade 
de conexão, a grande maioria dos estudantes participou das atividades remotas. A pesquisa demonstra, ainda, que 19,38\% declararam ter aprendido novas tecnologias. As famílias também tiveram que se adaptar para auxiliar os filhos na realização das atividades. Sendo assim, o período de pandemia impôs dois pontos estratégicos: ampliação dos conhecimentos tecnológicos e maior participação da família no processo de ensino-aprendizagem de seus filhos.

Outro ponto a ser analisado, buscando também os dados da ABED (2020), foi o fato de que 74,32\% dos professores têm realizado cursos online em sua rotina, assim, o contexto pandêmico trouxe a necessidade de aprimoramento. Assim, a profissão docente teve que ser reinventada, o docente passou a criar maneiras de acolher, motivar e acompanhar o processo de aprendizagem, além da necessidade da atualização tecnológica, pois o novo ambiente de sala de aula passou a ser virtual.

Em relação aos aplicativos utilizados nas aulas remotas, segundo a pesquisa da ABED (2020), os ambientes virtuais mais utilizados para distribuir conteúdo e promover interatividade pelos professores, além do AVA, são: WhatsApp 87,77\%, Google Meet 75,10\%, Zoom 27,81\%, Microsoft Teams 3,10\%, e-mail 45,02\%, Instagram 21,35\%, Facebook 13,39\%, Youtube 44,24\%, e o Telegram com 3,30\%. Diante dessas informações, percebemos que o aplicativo mais utilizado nas aulas foi o WhatsApp. Enfatizamos o uso do celular que, antes proibido em sala de aula, passou a ser um dos recursos mais valiosos para as aulas remotas. Portanto, Pretto (2013, p. 30) alerta que é importante "pensar a educação fortemente articulada com a cultura, com as telecomunicações, ciência e tecnologia". Dessa forma tais aplicativos demonstraram grande relevância para o processo de reinvenção educacional na pandemia.

Outra pesquisa realizada pela ABED (2020) buscou compreender se as atividades adotadas na pandemia por professores teriam potencial de continuarem sendo utilizadas no retorno às aulas presenciais. Os dados estão apresentados na Figura 1, seguinte:

Figura 1. Ações que pretendem continuar.

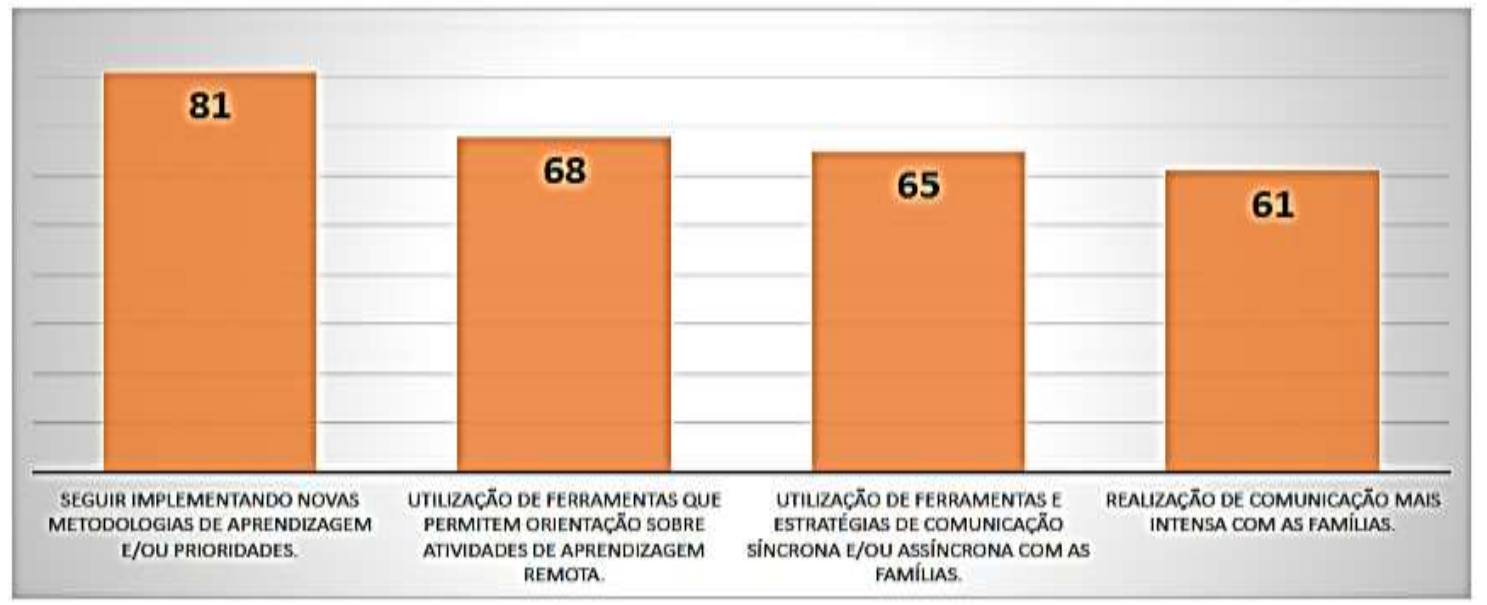

Fonte: ABED (2020).

\subsection{Mudança e interdisciplinaridade}

A Organização Mundial da Saúde reforçou a importância das atitudes de cada um para tentar controlar a disseminação da doença Covid-19 e manter a sustentabilidade dos sistemas de saúde durante a pandemia que vem ocorrendo desde 2020 em nosso país. Assim, vivemos um momento pandêmico em que as atitudes individuais refletiram em toda a sociedade, apresentando uma interligação. O paradigma educacional emergente também nos leva à percepção de que tudo ao nosso redor está interligado, nada existe de forma independente e sem conexão. Para Morin (2020, p. 06). "De fato, a importante revelação dos impactos que sofremos é que tudo aquilo que parecia separado está conectado, porque uma catástrofe sanitária envolve integralmente a totalidade de tudo o que é humano". 
Com isso, percebe-se a importância das ações isoladas diante das questões mundiais. Ao passo que essas vivências possibilitam refletir sobre a complexidade das questões planetárias. Morin (2000) aponta que um dos saberes fundamentais no educar para o futuro é a identidade terrena, que se relaciona ao pensar nossa casa comum.

Desse modo, as reflexões advindas da experiência pandêmica reforçam a necessidade de pensar a integração para a sustentabilidade na educação. Sendo desafiante para os educadores trabalhar a educação ambiental desenvolvendo a consciência terrena. A interdisciplinaridade é vista como uma facilitadora na inserção desses temas complexos (Fazenda, 2011).

Desta forma, acredita-se que a interdisciplinaridade pode facilitar a inserção de processos complexos no ambiente acadêmico como o da sustentabilidade, amenizando conflitos, integrando sujeitos, aproximando disciplinas e permeando temas de forma a acelerar trocas e aprendizados de saberes, em respeito às diferenças, aos ritmos, aos cenários e às histórias de vida, que o passado armazena e pela interdisciplinaridade existem possibilidades de integração entre o antigo e o moderno (Fazenda, 2011, p. 39).

Segundo Klein (1990) o termo interdisciplinaridade chegou ao Brasil por meio do estudo da obra de Georges Gusdorf, influenciando o pensamento de Hilton Japiassu no campo da epistomologia e Ivani Fazenda no campo da educação. Mas antes disso, conhecida internacionalmente como pioneira na educação interdisciplinar, a professora norte americana apresenta um estudo sobre o termo interdisciplinaridade. Para a autora, esse termo perpassa dois conceitos diferenciais essenciais: a distinção entre multidisciplinaridade e interdisciplinaridade e, ainda, entre interdisciplinaridade e transdisciplinaridade.

Morin (2000) menciona em suas obras a importância da transdisciplinaridade, caracterizada por proporcionar em sua prática, esquemas cognitivos capazes de atravessar as disciplinas, colocá-las em sinergia, proporcionar o pensar e o refletir.

A reforma educacional proposta por Morin pode ser iniciada com a articulação entre os saberes, sendo estimulada por uma educação que reconheça igualmente sua identidade terrena e, por meio desta, busque renascer o humano de modo conectado ao meio ambiente. Segundo Japiassu (1976), o trabalho interdisciplinar permite a abertura de um novo nível de comunicação abandonando a racionalidade tradicional. Assim Fazenda (2008, p. 119) menciona que "Interdisciplinaridade é uma nova atitude diante da questão do conhecimento, de abertura à compreensão de aspectos ocultos do ato de aprender e dos aparentemente expressos, colocando-os em questão".

Interdisciplinaridade é o processo que envolve a integração e engajamento de educadores, num trabalho conjunto, de interação das disciplinas do currículo escolar entre si e com a realidade, de modo a superar a fragmentação do ensino, objetivando a formação integral dos alunos, a fim de que possam exercer criticamente a cidadania, mediante uma visão global de mundo e serem capazes de enfrentar os problemas complexos, amplos e globais da realidade atual. (Luck, 1994, p. 64).

Nesse sentido, a interdisciplinaridade, diante de questões globais como a sustentabilidade, pode desempenhar a articulação do processo de ensino e de aprendizagem na medida em que se produzir como atitude (Fazenda, 1979); um modo de pensar consciente (Morin, 2005); um pressuposto na organização curricular (Japiassu, 1976); como fundamento para as metodologias do processo de ensino (Gadotti, 2004); ou ainda como elemento auxiliar na formação dos professores para enfrentar os desafios da educação na contemporaneidade.

Portanto, a interdisciplinaridade tem um papel importante, capaz de levar à integração das disciplinas, estimulando a mente humana para formular e solucionar questões globais, como a sustentabilidade, com práticas e métodos diversos que levem a uma nova forma de pensar, que interfiram no futuro de maneira positiva.

\subsection{Projetos ecoformadores interdisciplinares}

É necessário que a educação consiga despertar o desejo de cuidar do meio em que vivemos. Projetos ecoformadores são 
vistos como excelentes alternativas para trabalhar a educação ambiental, pois permitem que seja deixada de lado a visão imediatista e individualista, por um pensar de caráter colaborativo e social, visto que "estão encaminhados a formar cidadãos que valorizam, respeitam a natureza e promovem a melhoria social, cidadãos conscientes, comprometidos, criativos, livres, com projetos de vida, abertos ao saber, ao amor e à amizade, que têm a busca da felicidade como referência vital” (Torre, 2008, p. $34)$.

Os sujeitos da atual sociedade necessitam de criatividade e capacidade para enfrentar os problemas globais e melhorar as condições de vida no meio social de maneira sustentável. Assim, "Um Projeto Ecoformador representa um referencial de ensino e de aprendizagem baseado na autonomia, na transformação, na colaboração e na busca do desenvolvimento integral da pessoa" (Torre \& Zwierewicz, 2009, p. 155).

Na ecoformação, há a interação do aluno com o meio de forma contextualizada, sendo consideradas as experiências dos alunos, havendo a transposição para uma educação de princípios transdisciplinares "interação da pessoa ao seu entorno de forma sustentável”. (Praun \& Gonçalves, 2009, p. 144).

A disciplina especial Respeito à Natureza, a partir de práticas voltadas a sustentabilidade, desenvolvida em uma escola luzianense, é um exemplo de projeto criativo ecoformador, pois busca provocar a reflexão sobre os recursos naturais de forma consciente e responsável, problematizando as atitudes do homem em relação à natureza. Os Projetos Criativos Ecoformadores(PCE) são uma via metodológica para a educação, voltado ao desenvolvimento do pensamento complexo, da resiliência, tanto dos docentes quanto dos estudantes. (Torre \& Zwierewicz, 2011). Com o objetivo de contribuir com o bem-estar das pessoas, da sociedade e da natureza.

\section{Discussão}

\subsection{Uma escola sustentável e para todos}

A Escola Companhia das Letrinhas, onde desenvolvemos a nossa pesquisa, é uma escola de zona rural sem fins lucrativos, situada no município de Luziânia - GO, que oferece gratuitamente Educação Especial, Ensino Fundamental $\left(1^{\circ}\right.$ a $5^{\circ}$ ano), Educação Infantil, Estimulação Precoce e Educação de Jovens e Adultos. Atende com qualidade cerca de 300 estudantes (na faixa etária de 5 meses de idade até adultos e idosos) de baixa renda. Em regime de inclusão educacional, atende alunos autistas, com síndrome Down, deficiências mentais, físicas, auditivas, visuais etc.

A instituição é um espaço sustentável e para todos, sendo um ambiente acolhedor onde existe imaginação, criatividade, experimentação, aprendizagem na prática, invenção e uma crença de extrema gratidão à natureza, em que é ensinado aos alunos reverenciar a natureza, com diversas práticas que são exemplos para despertar a consciência ambiental nos educandos. Visto que a escola pode se tornar um espaço de contribuição para o despertar de uma consciência diante de padrões de percepção sobre a realidade, do sentido da vida e do ser humano nesse universo planetário que nos toca viver (Torre \& Zwierewicz, 2011).

Analisando a entrevista feita com a diretora da escola, pôde-se perceber que, por ser da zona rural, a instituição sempre teve uma relação muito forte com a preservação ambiental, que se consolidou numa prática de busca permanente da sustentabilidade e que seu lema hoje é uma escola sustentável e para todos. "A sustentabilidade é uma característica significativa da ecoformação" (Torre, 2008, p. 22).

Além das disciplinas tradicionais, existem mais três especiais na instituição: Ética do amor, Libras e Respeito à Natureza, sendo esta última o foco da nossa investigação. É valido ressaltar que a disciplina Ética do amor trabalha a relação com o outro e com o meio ambiente, no sentido de valorizar e respeitar tudo o que nos cerca, todas as relações que possamos ter tanto com o ser humano quanto com o meio ambiente. Segundo Torre (2008, p. 43), “a ecoformação como expressão do olhar transdisciplinar nos oferece uma visão dinâmica, interativa e ecossistêmica da educação, contemplando o educando como parte de um todo social e natural". 
A disciplina Respeito à natureza conta com atividades práticas voltadas para a sustentabilidade. A seguir, apresentamos o Quadro 1.

Quadro 1. Ações sustentáveis realizadas na escola.

\begin{tabular}{|c|c|c|}
\hline Atividade & Ação & Público \\
\hline Reciclagem & Redução e reaproveitamento do lixo. & Alunos \\
\hline Horta pedagógica & $\begin{array}{l}\text { É realizado o plantio de verduras e legumes com relação à disciplina } \\
\text { trabalhada em sala. Estudos sobre adubo, compostagem, curiosidades sobre } \\
\text { as hortaliças. }\end{array}$ & Alunos e família \\
\hline Feira & $\begin{array}{l}\text { Exposição do que foi plantado e a realização de receita com os alimentos } \\
\text { colhidos. Proposta de alimentação alternativa que é encaminhada às famílias } \\
\text { para reaproveitar alimentos. }\end{array}$ & Alunos e família \\
\hline Patrulha ecológica & $\begin{array}{l}\text { Diariamente alunos verificam se há lixos espalhados na escola e } \\
\text { eventualmente saem pelo cerrado fiscalizando. }\end{array}$ & Alunos \\
\hline Defesa do cerrado & $\begin{array}{l}\text { Evento em comemoração ao dia do cerrado, documentários criados pelos } \\
\text { alunos, estudo do bioma cerrado, colocação de placas de conscientização no } \\
\text { cerrado, proposta da } 1^{\text {a }} \text { Unidade de conservação do entorno. }\end{array}$ & $\begin{array}{l}\text { Alunos, família e } \\
\text { comunidade }\end{array}$ \\
\hline Espaço sustentável & $\begin{array}{l}\text { O material pedagógico e os papéis utilizados nas aulas são reaproveitados. A } \\
\text { construção das salas de aula foi feita com material aproveitado. As pias são } \\
\text { feitas de pneus e os bebedouros vêm de um freezer reaproveitado. As salas } \\
\text { recebem nomes de elementos da natureza. }\end{array}$ & $\begin{array}{l}\text { Comunidade escolar } \\
\text { e alunos }\end{array}$ \\
\hline $\begin{array}{l}\text { Associação de Artesãos Amigos da } \\
\text { Escola Companhia das Letrinhas. }\end{array}$ & $\begin{array}{l}\text { A reutilização e reciclagem de materiais promove uma "cadeia produtiva } \\
\text { sustentável", evitando o desperdício, gerando renda com as oficinas } \\
\text { artesanais e pedagógicas a partir da comercialização dos objetos } \\
\text { transformados, dentre outros benefícios. Uma importante ação que decorreu } \\
\text { desta prática verde foi a criação da Associação de Artesãos Amigos da Escola } \\
\text { Companhia das Letrinhas. }\end{array}$ & Alunos e mães \\
\hline Reafeto & $\begin{array}{l}\text { Envio de material pedagógico reaproveitado para a manutenção das aulas } \\
\text { remotas. }\end{array}$ & Alunos e família \\
\hline
\end{tabular}

Fonte: Autores.

A Escola desenvolve metodologias e tecnologias educacionais, sociais e ambientais que promovem não apenas a inclusão educacional, mas, contribui com o desenvolvimento socioambiental da comunidade. Quando há a relação dos conteúdos com a vida cotidiana dos alunos, poderá ser aumentado o envolvimento e o interesse com a aprendizagem. E partindo das necessidades e interesse dos estudantes, as atividades realizadas na escola podem ser espaços de ecoformação. Segundo o que menciona Santos (2010), envolvem o estudante em atividade global, intelectual, de criação, expressão verbal, escrita, plástica ou outro tipo.

O reaproveitamento dos restos orgânicos proveniente do lanche é utilizado para a compostagem que serve de adubo para a horta, juntamente com as cascas dos ovos vindas da fábrica de pão de queijo, mais uma ação realizada pela instituição para o levantamento de verbas. Além disso, conta com um minhocário para produção de húmus para ser utilizado na horta.

A horta é um espaço pedagógico muito importante onde se realiza o plantio de verduras e legumes, sendo feita uma relação com as demais disciplinas. As crianças aprendem sobre os tipos de adubo, compostagem, curiosidades sobre as hortaliças e depois compartilham o aprendizado com as outras turmas, acompanham e veem o crescimento até a colheita. Depois é realizada uma feira para expor o que foi plantado e ocorre a realização de receita com os alimentos colhidos. Também é feito o envolvimento com a família sendo encaminhada a proposta de alimentação alternativa com dicas de como reaproveitar alimentos. De modo que o trabalho feito na escola seja ampliado até as famílias para uma maior conscientização.

Os alunos realizam diariamente uma patrulha ecológica dentro da escola verificando se tem algo errado com a natureza, como lixos espalhados ou queimadas. Eventualmente esta patrulha sai pelo cerrado para verificar as condições de preservação. 
O trabalho em prol da defesa do cerrado já vem sendo realizado há 12 anos, e conta com evento de comemoração ao dia do cerrado, eventos em parceria com entidades, órgãos públicos, ambientalistas. Além da criação de documentários redigidos e filmados pelos alunos em defesa do cerrado, estudo do bioma cerrado, colocação de placas de conscientização no cerrado, criação da $1^{\text {a }}$ Unidade de conservação do entorno com proposta encaminhada à prefeitura Municipal de Luziânia para a criação de um parque ecológico em frente à escola.

A diretora afirma que sempre tiveram a crença de reaproveitar o que a natureza oferece. E conta com a prática dos três $R$ : Reduzir, Reutilizar e Reciclar, assim, a prática vai desde a redução até o reaproveitamento do lixo. O material pedagógico e papéis utilizados nas aulas são reaproveitados, a construção das salas também foi com material aproveitado. Os espaços da escola são sustentáveis, as pias são feitas de pneus os bebedouros vem de um freezer reaproveitado. A unidade ainda conta com a praça das mangueiras, bosque encantado, lago de carpas (espaço terapêutico para crianças autistas) biblioteca de vidro em meio ao bosque. Sendo um espaço totalmente ecológico, fazendo com que os estudantes aprendam pelo exemplo, pois vivenciam na prática as ações sustentáveis.

Na busca dessa integração com o meio ambiente, a concepção de inclusão se faz presente na escola, as salas/turmas recebem os nomes de elementos da natureza, pois acredita-se que desta forma todos têm a mesma importância nessa relação, conforme demonstram as palavras da diretora da escola:

"Somos igualmente belos e importantes nessa relação com a natureza porque nós também fazemos parte dela, então para ninguém ficar mais importante do ponto de vista hierárquico todo mundo na escola é igual".

Uma importante ação que decorreu desta prática verde foi a criação da Associação de Artesãos Amigos da Escola Companhia das Letrinhas, formada por alunos e mães de alunos que, trabalhando de forma solidária e criativa, gera renda e oportunidade para os participantes e para a própria escola, com a venda dos produtos confeccionados.

No momento de pandemia, foi criado um programa com a confecção de material pedagógico e atividades personalizadas que são levadas às sextas-feiras em algumas casas, ou em paradas de ônibus para os alunos, e recolhendo as atividades feitas para correção.

No período de pandemia no ano 2020, não está tendo compostagem, pois não está tendo merenda. Mas o trabalho sustentável continuou mesmo com as aulas remotas, pois, na escola, as professoras continuaram o cultivo da horta de maneira interdisciplinar, por exemplo, para um trabalho pedagógico com a letra $\mathrm{P}$ planta-se pepino, envolvendo algo concreto e significativo, para trabalhar a família silábica e iniciar o processo de alfabetização. Além disso, foram enviadas para as famílias as mesmas sementes plantadas na escola, dois tipos de adubo para que as famílias pudessem construir uma horta em casa, sendo acompanhada pelas fotos enviadas aos professores. Foi informado que a ação foi produtiva, com grande participação de alunos e familiares, e que provavelmente será realizada também no ano de 2021 caso continue o ensino remoto.

As ações realizadas pela escola permitem o aprendizado pelas vivências, pois são os próprios alunos que vão para a horta e colocam a mão na terra, o que torna o aprendizado alegre e significativo. A aprendizagem é algo que o sujeito constrói por si mesmo por meio da interação com as informações que o meio disponibiliza (Maturana \& Varela, 2001). Visto que a instituição exerce um papel fundamental na formação de cidadãos criativos e comprometidos, que possam identificar problemas da sua realidade e solucioná-los por meio do que aprendem.

Educar para a sustentabilidade vai muito além do cuidado com o meio ambiente e tem como pressupostos o ensino de valores, o cuidado com o planeta e com as pessoas. A diretora da escola menciona que é importante:

"Que gente acredite na importância desse trabalho sustentável e que, a mesma importância que é dada para as questões macrovisão que falamos do planeta, água, Amazônia, da mata atlântica. Quando falamos em sustentabilidade não 
estamos falando dessa macrovisão, mas também da nossa prática no dia a dia mudando nosso ambiente nossos recursos, reaproveitando os recursos que temos e cada um pode fazer sua parte. Pois fala-se muito do desmatamento, da camada de ozônio, das condições climáticas, quando na verdade a sustentabilidade começa em cada um de nós nas menores práticas e principalmente nos pequenos que vão crescer e fazer grandes transformações."

A entrevistada ainda menciona que o grande desafio enfrentado para essa prática sustentável é a manutenção da escola por ser instituição filantrópica. As questões ambientais não podem ser trabalhadas apenas em datas comemorativas, devem ser uma prática cotidiana, pois assim transforma a postura da escola e essa transformação tem um grande potencial de chegar às famílias e comunidade, uma vez que as crianças aprendem a partir do contato na prática e, quando percebem esses exemplos diários na escola, elas crescem com a consciência ambiental. O trabalho desenvolvido nesta escola é possível ser realizado em qualquer outra realidade, basta ter uma gestão que acredite na importância da sustentabilidade e o engajamento de todos profissionais envolvidos.

\section{Considerações Finais}

Diante de um mundo cheio de questões complexas, a crise pandêmica trouxe várias mudanças para a sociedade e, na tentativa da educação de se adaptar ao novo modelo imposto, nasce um novo pensar a educação. Professores passaram a buscar por mais aprimoramento profissional e afirmam que irão levar práticas aprendidas nas aulas remotas para o ensino pós-pandemia. Uma vez que a escola mais do que antes desempenhou a função social apoiando emocionalmente e criando formas de comunicação com o aluno para a manutenção das aulas.

Salienta-se que a teoria da complexidade, no entendimento de Edgar Morin, traz a necessidade de uma mudança educacional. Visto que o momento pandêmico promoveu pequenas mudanças que podem ser vistas como o início de um novo caminhar.

E diante da interferência das atitudes individuais e sociais na pandemia ressurge a responsabilidade de cada sujeito frente às questões planetárias e se torna mais evidente a necessidade de um trabalho que envolva as questões complexas na educação. Dessa forma, a interdisciplinaridade tem grande potencialidade de desenvolver nos educandos a consciência ambiental.

Portanto, ao analisar o trabalho desenvolvido na Escola Companhia das Letrinhas, na cidade de Luziânia, percebemos que a instituição desempenha um papel de grande relevância para o desenvolvimento de cidadãos conscientes sobre as questões ambientais e que o trabalho desenvolvido pode ser entendido como projeto ecoformador, capaz de desenvolver no aluno a responsabilidade e o cuidado com a natureza.

Este estudo não consegue esgotar toda a temática sobre a pandemia e a interdisciplinaridade na educação, bem como essa não é nossa pretensão. Sabe-se que o pensar a educação deve ser constante, estimulando sua reinvenção e a inserção de novas estratégias que possam aproximar o ensino das causas planetárias por meio da transdisciplinaridade, porém para sua ampliação é preciso tempo para que seja desenvolvida mudanças positivas.

Nesse sentido, o trabalho voltado para as questões planetárias na escola nos leva a perceber que se fazem necessários mais estudos relacionados ao tema na educação para formar nos alunos a consciência sobre as questões planetárias. Bem como o advento da pandemia nos revelou que as situações globais podem interferir drasticamente na vida de cada pessoa, o mesmo acontece com os problemas sofridos pelo meio ambiente. Como também as estratégias utilizadas na escola podem ser utilizadas em outras instituições, podendo ser adaptadas a qualquer realidade, e que poderão contribuir para a consciência planetária.

\section{Referências}

ABED. (2020). Associação Brasileira de Educação a Distância. Educação Básica: Atividades Remotas 2020 Http://Www.Abed.Org.Br/Arquivos/Result Ado_Pesquisa_ABED_Atividades_Remotas_Na_Educacao_Basica_2020_George_Bento.Pdf. 
Fazenda, I. C. A. (2008) O que é Interdisciplinaridade? Cortez.

Fazenda, I. C. A (2011) A Interdisciplinaridade. / Grupo de Estudos e Pesquisa em Interdisciplinaridade (GEPI) - Educação: Currículo - Linha de Pesquisa: Interdisciplinaridade - PUCSP.

Fazenda, I. C. (1979) A Integração e interdisciplinaridade no ensino brasileiro: efetividade ou ideologia. Loyola.

Berg, J., Vestena, C. L. B., \& Costa L C. (2020) Criatividade e Autonomia em Tempo de Pandemia: Ensaio Teórico a partir da Pedagogia Social. Revista Internacional de Educación para la Justicia Social.

Bogdan, R. C. \& Biklen, S. K., (1994) Investigação qualitativa em Educação: fundamentos, métodos e técnicas. Porto Editora.

Gadotti, M. (1999) Interdisciplinaridade - atitude e método. http://www.paulofreire.org/moacir_gadotti/artigos/portugues/filosofia_da_educaçao.

Gadotti, M. (2004) História das ideias pedagógicas. Editora Ática,

Japiassu, H. (1976) Interdisciplinaridade e patologia do saber. Imago.

Klein, J. T. (1990) An Interdisciplinary Lexicon In: Interdisciplinarity: History, Theory \& Practice. Wayne State University Press, Detroit.

Lück, H. (1994) Pedagogia interdisciplinar-fundamentos teórico-metodológicos. Vozes.

Maturana, H. (2002). Emoções e Linguagem na Educação e na Política: Editora UFMG.

Menchén, F. (2013) A escola galática, a escola criativa transformadora: uma nova consciência. In Torre, S., Pujol, M. A., Silva, V. L. S. Inovando na sala de aula: instituições transformadoras. Nova Letra.

Maturana, H., \& Varela, F. (2001) A árvore do conhecimento. Trad. Humberto Mariotti e Lia Diskin. Palas Athena.

Morin, M. C. (1997) O paradigma educacional emergente. Papirus.

Morin, E. (2007) Introdução ao pensamento complexo. Sulina.

Morin, E. (2000). Os sete saberes necessários à educação do futuro. Cortez.

Morin, E. (2005). Educação e complexidade, os sete saberes e outros ensaios. Cortez.

Morin, E. (2015). A via para o futuro da humanidade. Bertrand Brasil.

Morin, E. (2020). Um festival de incertezas. http://www.ihu.unisinos.br/78-noticias/599773-um-festival-de-incerteza-artigo-de-edgar-morin

Praun, A. G., \& Gonçalves, D. K. (2009) Educação inclusiva: criatividade e ecoformação no entorno escolar. In ZWIEREWCZ, M., TORRE, S. De La. Uma escola para o Século XXI: Escolas criativas e resiliência na educação. Insular.

Pretto, N. de L. (2013). Reflexões: ativismo, redes sociais e educação. UFBA.

Reimers, F. M., \& Schleider, A. (2020). A framework to guide na education response to the COVID-19 Pandemic of 2020. OECD.

Richardson, R. J. (1999). Pesquisa social: métodos e técnicas. Atlas

Santos, A., Barros S. S. (2010). Métodos interativos na perspectiva da transdisciplinaridade. In Torre, S. et al. (Coords). Innovación y Creatividad. Giad.

Santos, B. de S. (2020). A cruel pedagogia do vírus. Almedina S. A.

Skinner, D \& Tagg, C. \& Holloway, J., (2000). And research: the pros and cons of qualitative approaches. Management Learning.

Torre, S. (2008). Criatividade aplicada: recursos para uma formação criativa. Madras

Torre, S., \& Zwirewicz, M. (2009). Projetos criativos ecoformadores. In Zwirewicz, M., Torre, S. Uma escola para o século XXI: escolas criativas e resiliência na educação. Insular.

Torre, S., \& Zwirewicz, M. (2013). Projetos Criativos Ecoformadores (PCE): uma via metodológica desde e para o paradigma da complexidade. In: Torre, S., Pujol, M. A., Silva, V. L. S. (Org.). Inovando na sala de aula: instituições transformadoras. Nova Letra.

Torre, S., \& Zwirewicz, M. (2011). Formação docente em projetos criativos e ecoformadores. Revista Electrónica de Investigación y Docencia. Nova Letra. 